УДК 550.832 .54

\title{
ИССЛЕДОВАНИЕ УГЛЕРАЗВЕДОЧНЫХ СКВАЖИН МЕТОДОМ ИМПУЛЬСНОГО НЕЙТРОН-НЕЙТРОННОГО КАРОТАЖА
}

\author{
Фоменко Николай Евгеньевич 1 , \\ fnegeophyskohle@yandex.ru
}

\author{
Попов Виктор Владимирович², \\ viktor_popov_34@mail.ru
}

Коваленко Андрей Сергеевич 3 , a_kovalenko_77@mail.ru

1 Южный федеральный университет, Россия, 344090, г. Ростов-на-Дону, ул. Зорге, 40.

2 Южно-Российский политехнический университет, Россия, 346428, г. Новочеркасск, ул. Просвещения, 132.

${ }^{3} \mathrm{AO}$ «Всероссийский научно-исследовательский геологоразведочный институт угольных месторождений», Россия, 344090, г. Ростов-на-Дону, пр. Стачки, 200/1, корп. 3.

\begin{abstract}
Актуальность работы определяется необходимостью оптимизации комплекса геофизических исследований углеразведочных скважин посредством импульсного нейтрон-нейтронного каротажа. Постановка проблемы обусловлена современными тенденциями развития угольной отрасли и новыми аппаратурными и техническими разработками в разведочной и промысловой геофизике.

Цель: показать возможности и результативность импульсного нейтрон-нейтронного каротажа в углеразведочных скважинах на материалах опытно-экспериментальных работ в Восточном Донбассе.

Объект: каротажные диаграммы импульсного нейтрон-нейтронного каротажа, зарегистрированные в углеразведочных скважинах Восточного Донбасса.

Методы: анализ каротажных кривых импульсного нейтрон-нейтронного каротажа на предмет результативности использования метода в стандартном комплексе для решения задач, поставленных геологической службой по выделению: 1) целевых объектов, т. е. угольных пластов с определением их положения в разрезе; 2) пород, вмещающих угольные пласты.

Результаты. Выполнено обоснование применения импульсного нейтрон-нейтронного каротажа для изучения геологических разрезов угольных скважин. Изучены качественные и количественные характеристики времени жизни тепловых нейтронов в породах угленосной толщи. Показаны возможности метода по оценке марочного состава углей и их зольности. Произведено сопоставление каротажных диаграмм, зарегистрированных на различных временных задержках и с различной скоростью подъёма скважинного прибора, на предмет выбора оптимальных условий геофизических работ этим методом. Установлено, что все литологические разности, включая тонкие угольные пласты, однозначно выделяются методом импульсного нейтрон-нейтронного каротажа. Выполнен анализ разрешающей способности импульсного нейтрон-нейтронного каротажа на фоне каротажных кривых поискового комплекса геофизических исследований скважин, включая методы электрического, радиоактивного, акустического каротажа и кавернометрию. Сделан акцент на положительных сторонах и недостатках метода гамма-гамма каротажа с мягким источником (ГГК-С). Предложено при наличии организационно-технических сложностей заменять исследования ГГК-С импульсным нейтрон-нейтронным каротажем.
\end{abstract}

\section{Ключевые слова:}

Импульсный нейтрон-нейтронный каротаж, уелеразведочная скважина, время жизни тепловых нейтронов, рациональный комплекс каротажа, пласты аргиллитов, алевролитов, песчаников и известняков, Восточный Донбасс.

\section{Введение}

Импульсный нейтронный каротаж (ИНК) получил развитие в отечественной практике геофизических исследований скважин в начале 60-х гг. минувшего столетия. За прошедшее время созданы современная аппаратура и интерпретационное обеспечение. Метод широко применяется в настоящее время в РФ и за рубежом, особенно в нефтегазовой геологии [1-6]. Физико-геологическими предпосылками возникновения и становления ИНК, как известно, является наличие водородосодержания в горных породах за счёт их пористости, нефте-, газо- и водонасыщенности. Наиболее прогрессивной технологией ИНК яВляется импульсный нейтрон-нейтронный каротаж (ИННК), в котором горные породы, пересечённые скважиной, облучаются кратковременными потоками быст- рых нейтронов, следующих через определённые промежутки времени. В этом случае соотношение плотностей тепловых нейтронов в пластах горных пород зависит преимущественно от поглощающих свойств этих пород. Существенное преимущество ИННК состоит в: 1) отсутствии стационарных источников нейтронов, требующих содержания в специальных контейнерах; 2) создании значительно большой (до 15 МэВ) энергии нейтронов, испускаемых скважинным генератором нейтронов, что позволяет исследовать околоскважинное пространство в радиусе до 0,8 м; 3) многоканальности регистрирующей аппаратуры с соответствующим выбором времени задержки $\left(\tau_{3}\right)[7,8]$.

В 70-80-х гг. двадцатого столетия были выявлены предпосылки использования ИННК и осуществлено 
первое опробование метода на угольных месторождениях [9, 10]. Результаты исследований показали, что угли и вмещающие их породы, несмотря на низкое в них водородосодержание, можно безошибочно разделять по средним временам жизни тепловых нейтронов. Также предложена методика определения по данным ИННК зольности углей в скважинах [11]. Однако, в отличие от массового использования ИННК в нефтяной отрасли, на угольных месторождениях эти исследования не являлись систематическими. В те годы существующими поисковым и детализационным комплексами геофизических исследований скважин (ГИС) на угольных месторождениях (методы КС, БК, ГК, ГГКП, ГГК-С, АК, каверно- и инклинометрия) [12] положительно решались геологические задачи по определению глубины залегания, мощности, структуры, зольности углей, физико-механических свойств вмещающих пород и др. Применение ИННК в этих комплексах требовало до- и переоборудования серийных каротажных станций, имеющих ограниченное число регистрирующих каналов и стендовых ниш для размещения новых аппаратурных панелей.

В настоящее время в РФ геологоразведочные работы ориентированы на поиски энергетических и коксующихся углей особо ценных марок и выполняются в ограниченных объёмах в Южно-Якутском бассейне (республика Саха), Печорском бассейне (республика Коми), Кузнецком и Омсукчанском бассейнах (Кемеровская и Магаданская области), месторождениях угля на о. Сахалин, в Приморском крае и республике Бурятия. Геофизические исследования скважин часто выполняются урезанным комплексом методов, в том числе из-за отсутствия возможностей хранения и перевозки радиоактивных источников. В существующих единичных каротажных отрядах в большинстве случаев ещё не осуществлён переход на освоение и производственное применение новых агрегатированных каротажных комплексов и технических средств, позволяющих выполнять исследования в отдалённых друг от друга регионах, несмотря на наличие современных прогрессивных разработок в нефтяной и других отраслях [13-19]. Всё это предопределяет необходимость оптимизации комплекса геофизических исследований углеразведочных скважин, в том числе и за счёт метода ИННК. Угольный каротаж должен представляться в виде многоканальной цифровой компьютеризированной каротажной станции с комплексными скважинными приборами [20].

\section{Физико-геологические предпосылки применения импульсных нейтронных методов на угольных месторождениях}

Угли, в ряду их метаморфизма (бурые, каменные, антрациты), отличаются от вмещающих пород вещественным составом и физическими свойствами [21]. Для ИННК основным показателем является время жизни тепловых нейтронов $\tau$. Для этого в породах изучается временная зависимость распределения плотности тепловых нейтронов. На рис. 1, а приведены рассчитанные кривые вероятностного распределения (Р) среднего времени жизни нейтронов в породах угленосной толщи Восточного Донбасса. Из рисунка следует, что все литологические разности уверенно разделяются по показателю $\tau$, что создаёт предпосылки для успешного примене- ния ИННК на угольных месторождениях. Наибольший размах вариации имеют кривые песчаников, углей и известняков, что обусловлено изменениями их вещественно-петрографического состава и текстурноструктурных особенностей. Песчаники, например, различаются между собой по крупности зерна и микрослоистости в зависимости от речной, переходной или морской групп фаций; известняки могут «переходить» в мергелистую группу, а углям свойственны колебания зольности, вызванной примесными включениями глинистых и др. минералогических фракций.

На рис. 1, б представлен осреднённый элементный состав углей для условий Восточного Донбасса. Заметим при этом, что, согласно теоретическим основам ИНК, для показателя $\tau$ определяющим является параметр отношения сечения захвата $\left(\sigma_{31}\right)$ к массовому числу элемента $\left(\mathrm{A}_{\mathrm{i}}\right)$, т. е. $\sigma_{31} / A_{i}$. Этот параметр максимален для водорода и, по отношению к нему, меньше для азота в 2 раза, для серы в 20 раз, для углерода - в 1000 раз и для кислорода - в 26000 раз. Следовательно, время жизни тепловых нейтронов для органической части угля $\left(\tau_{\text {огг. }}\right)$ определяется в основном содержанием водорода $(\mathrm{H})$, азота $(\mathrm{N})$, серы $(\mathrm{S})$, и почти не зависит от содержания углерода $(\mathrm{C})$ и кислорода $(\mathrm{O})$. Наибольшее влияние на $\tau_{\text {орг }}$, соответственно, оказывает содержание водорода, а изменение процентного содержания $\mathrm{N}$ и $\mathrm{S}$ мало сказывается на $\tau_{\text {орг }}$ (рис. 1,8 ). В практических целях, если снять значения $\tau_{\text {угл }}$ с каротажной диаграммы, можно по графику, приведенному на рис. 1, 2, определить $\tau_{\text {орг }}$ и далее по графику 1, в оценить процентное содержание водорода. Максимальная ошибка, которая может быть при определении $\tau_{\text {овг }}$, составляет 100 мкс. Это приводит к ошибке оценки водородосодержания 0,2\%. Следовательно, зная содержание Н в органической части угля, можно определить марку угля (содержание Н характеризует степень метаморфизма углей).

Расчёты и построения показали возможность оценки по данным ИННК зольности углей (А). С этой целью был взят постоянный состав органической части угля и золы для марок A1 и А2. Пористость этих марок не превышает первых процентов, поэтому расчёты графиков зависимости среднего времени жизни тепловых нейтронов в углях различной зольности произведены для нулевой, пяти и десяти процентной пористости (рис. 2,a).

Значения скорости счёта можно определять по результатам каротажа. Коэффициент пористости известен по результатам лабораторных определений. Удовлетворительная точность достигается, если процентное содержание водорода в органической части угля колеблется в пределах от 1,1 до 1,6 \%. Время жизни тепловых нейтронов $\tau$ рассчитывается по формуле:

$$
\tau=\frac{t_{32}-t_{31}}{\ln N\left(t_{\text {пл. } 31}\right)-\ln N\left(t_{\text {пл. } 32}\right)},
$$

где $t_{1}, t_{32}$ - временные задержки, на которых производится снятие скорости счёта $(N)$ в анализируемом пласте.

Другой, не менее точный, способ определения $\tau$ графический. Для этого на прямолинейном участке кривой спада плотности тепловых нейтронов или на касательной к ней, в правой части, находят точки, в которых скорость счёта отличается на единицу, т. е. $\left(\ln N\left(t_{1}\right)\right.$ $\ln N\left(t_{2}\right)=1$. При этом $\tau$ соответствует отрезку $\left(t_{1}-t_{2}\right)$ на оси абсцисс (рис. 2, б). Разработаны и другие способы определения зольности углей по данным ИНК [11]. 

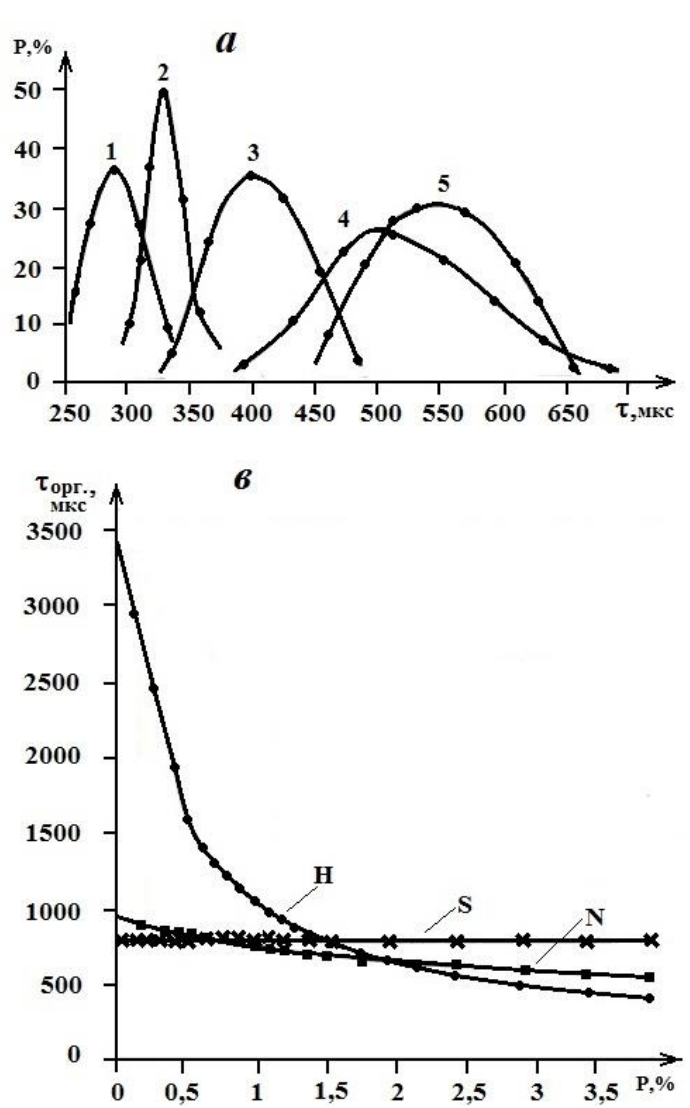

б
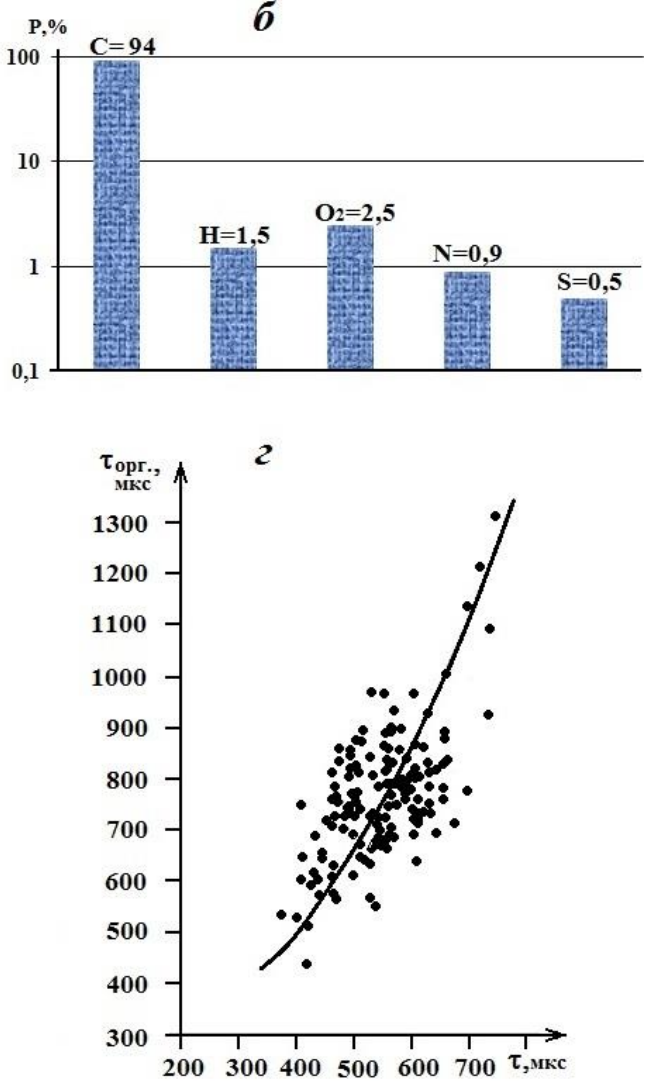

Рис. 1. Нейтронные свойства угленосной толщи: а) среднее время жизни нейтронов (1-аргиллит, 2 - алевролит, 3 - песчаник, 4 - уголь, 5 -известняк); б) элементный состав углей марки А1 и А2; в, г) среднее время жизни тепловых нейтронов в органической части угля при различном содержании водорода, серы и азота (в) и при увеличении зольности (2)

Pic. 1. Neutron properties of coal-bearing stratum: a) mean neutron lifetime (1-argillite, 2 - aleurolite, 3 - sandstone, 4 coal, 5 -limestone); б) element composition of coals of A1 and A2 marks; 6 , 2) thermal neutron lifetime in organic part of coal at different content of hydrogen, sulfur and nitrogen (B) and by increasing ash content (2)

$a$

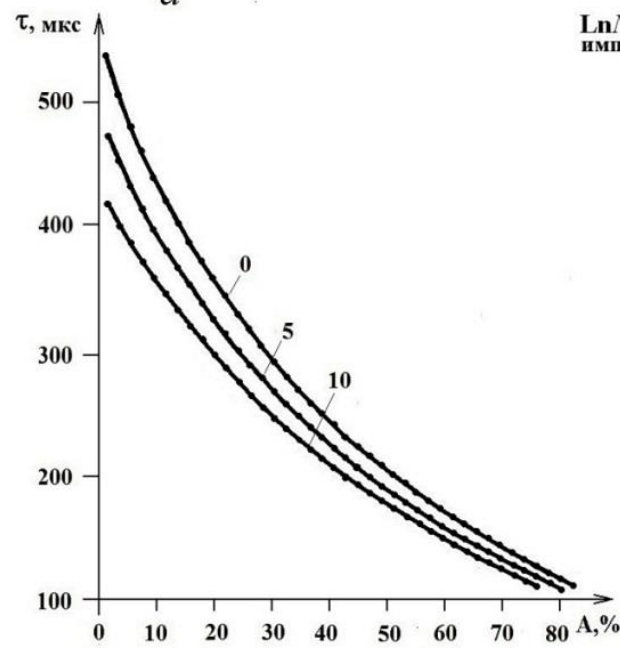

6

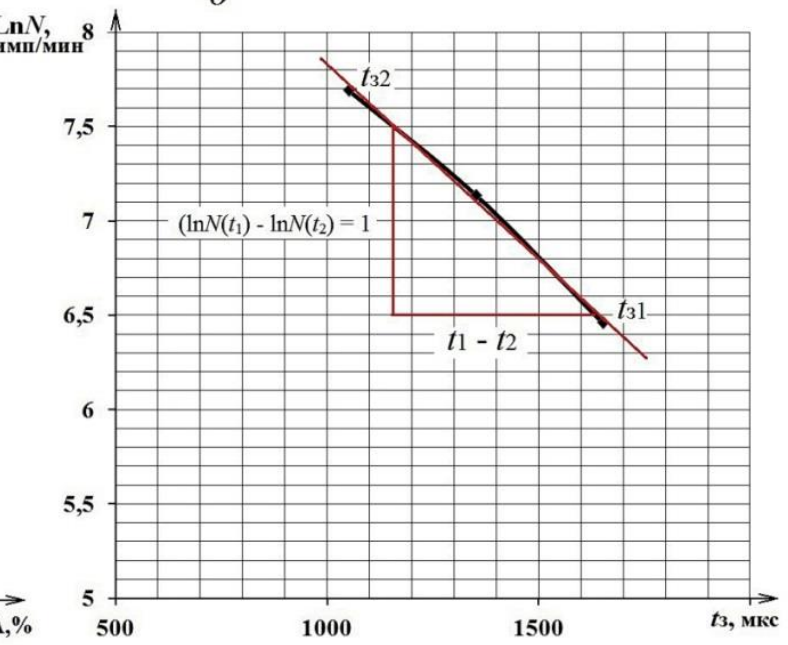

Рис. 2. Зависимость среднего времени жизни тепловых нейтронов углей марки А1 и А2 от их зольности (а) и пример определения плотности тепловых нейтронов графическим способом (б). Шифр кривых на фрагменте а соответствует коэффичиенту пористости

Pic. 2. Dependence of mean thermal neutron lifetime of A1 and A2 mark coals on their ash content (a) and example of density thermal neutron definition through graphic method (6). The cipher of curves on the fragment a corresponds to the porosity coefficient 


\section{Выбор оптимальных условий регистрации диаграмм ИННК}

Эксперименты в углеразведочных скважинах проводились аппаратурой ИГН-6, где источником возбуждения нейтронов служила нейтронная трубка НТ-16 с частотой посылок импульсов нейтронов 20 Гц и длительностью импульсов нейтронов 3 мкс (выход $5 \times 10^{7}$ нейтр./c). Детектором служил гелиевый счетчик
СНМ-18-1. Задачи исследований состояли в регистрации каротажных кривых на различных временных задержках $\left(t_{3}\right)$ и при разной скорости подъёма скважинного прибоpa $(V)$.

На рис. 3, 4, а сопоставлены диаграммы ИННК на различных задержках, зарегистрированные в углеразведочной скважине в интервалах разреза с мощными пластами известняка и песчаника.

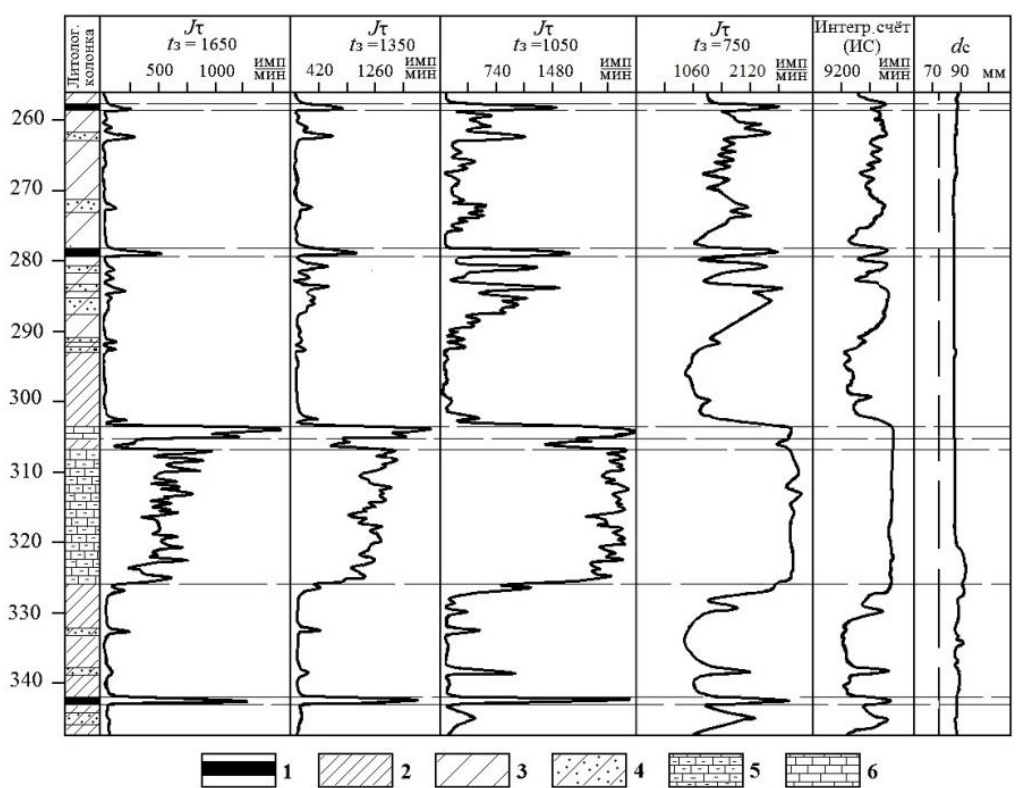

Pис. 3. Сопоставление диаграмм ИННК, зарегистрированных в углеразведочной скважине на различных задержках в Восточном Донбассе: 1 - уголь; 2 - аргиллит; 3 - алевролит; 4 - алевролит крупнозернистый (песчаный); 5 - известняк глинистый (мергель); 6 - известняк

Pic. 3. Matching the Pulsed Neutron-Neutron Logging logging (PNNL) diagrams registered in the coal exploration wells with different time delays in the Eastern Donbass: 1 -coal; 2 -argillite; 3 -aleurolite; 4 -aleurolite coarse-grained (sandy); 5 - limestone clayey (marl); 6 - limestone

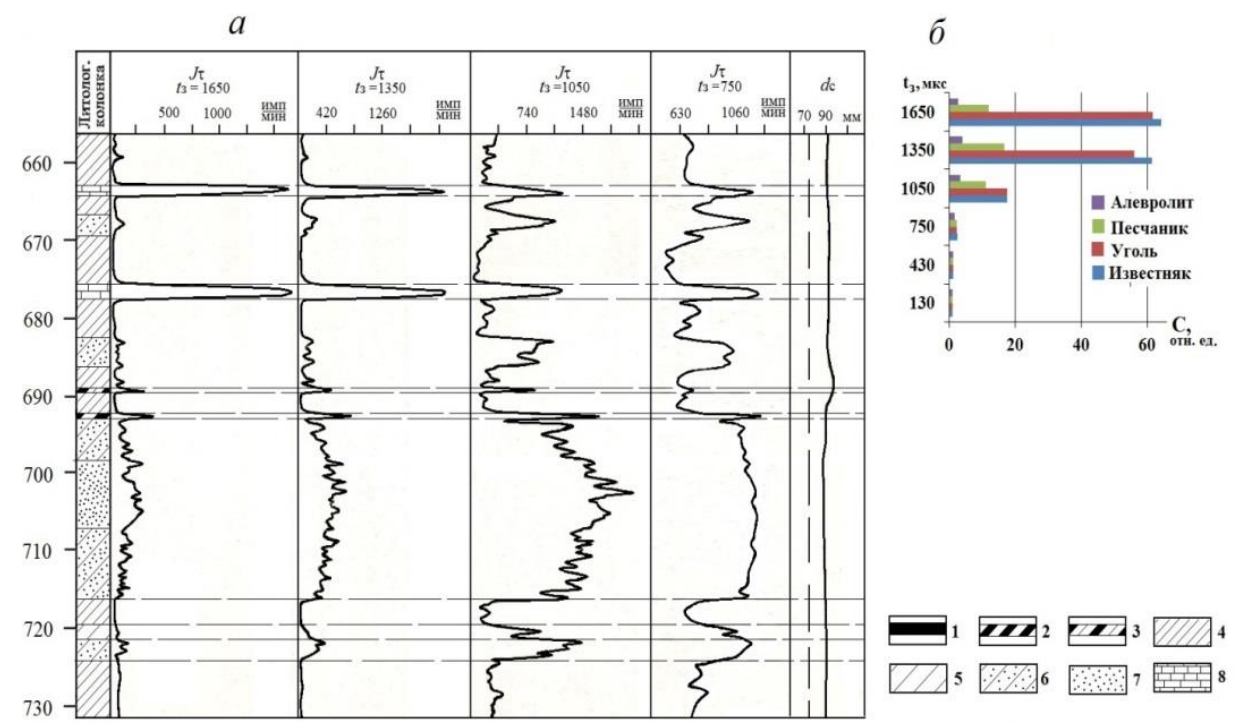

Pис. 4. Сопоставление диаграмм ИННК, зарегистрированных в углеразведочной скважине на различных задержках (а) и гистограмма соотношения амплитудных значений кривых ИННК для углей и вмещающих пород (б) 6 Восточном Донбассе: 1 - уголь, 2 - сланеи углистый, 3 - сланеи углисто-глинистый, 4 - аргиллит, 5 - алевролит, 6-алевролит крупнозернистый (песчаный), 7 -песчаник, 8 -известняк

Pic. 4. Matching the PNNL diagrams registered in the coal exploration well at different delays (a) and a histogram of the ratio of the amplitude values of the PNNL curves for coals and host rocks (б) in the Eastern Donbasse: 1 - coal, 2 shale coal, 3 - shale carbonaceous-argillaceous, 4 - argillite, 5 - aleurolite, 6 - aleurolite coarse-grained (sandy), 7 - sandstone, 8 - limestone 
Из приведенных данных следует, что метод ИННК обладает высокой разрешающей способностью в интервале задержек 700-2000 мкс. На этих задержках все пересечённые скважиной литологические разности, включая тонкие пласты углей, углистых сланцев и известняков, выделяются однозначно. Это следует и из диаграммы значений скорости счёта тепловых нейтронов для пластов известняков, углей, песчаников и алевролитов по отношению к аргиллитам, в которых поглощение этих нейтронов максимально (рис. 4,6 ). Полученные результаты соответствуют расчётным значениям (рис. 1, $a$ ). Здесь следует отметить, что современные аппаратурные разработки и компьютерное обеспечение каротажа позволяют производить одновременную регистрацию сколь угодного количества кривых на различных задержках, что предопределяет возможности внутриметодного комплексирования. Например, на задержках 750 и 1050 мкс проявляется общая ситуационная картина литологической характеристики угленосной толщи, а на более высоких временных задержках - 1350 и 1650 мкс - создаются предпосылки разделения близких по описательным признакам и минералогическому составу литотипов (песчаники и пес- чаные алевролиты, а также уголь и углистые сланцы). Разрешающая способность ИННК в определении мощности (толщины) пластов и пропластков оценивается величиной порядка $0,06-0,08$ м при длине каротажного зонда $L=0,4$ м. Это подтверждается теоретическими расчётами, согласно которым мощность выделяемых пропластков очень мало зависит от длины зонда, поскольку максимальное влияние на детектор оказывает только небольшая область, непосредственно прилегающая к нему (детектору) [7]. Существует оптимальный зонд, для которого плотность тепловых нейтронов выходит на асимптоту при минимальной задержке. Было подсчитано, что оптимальная длина зонда $\left(L_{\text {опт. }}\right)$ для антрацита равна 32 см. На рис. 5, а сопоставлены кривые ИННК и бокового каротажа (БК) в интервале мощного пласта известняка сложного строения. Как видно из рисунка, тонкий слой чистого известняка, оконтуренный в центральной части пласта двумя слоями мергеля, можно однозначно выделить методом ИННК при $L_{\text {опт. }}=0,4$ м в комплексе с методом БК. Это же относится и к пропластку алевролита в пласте аргиллита на глубине 303,4 м.

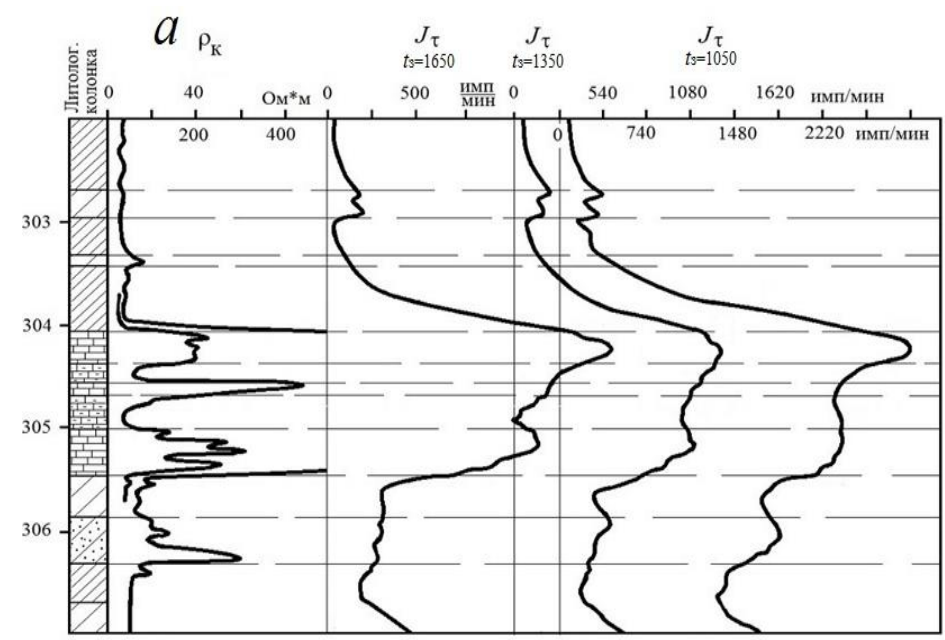

$\sigma$

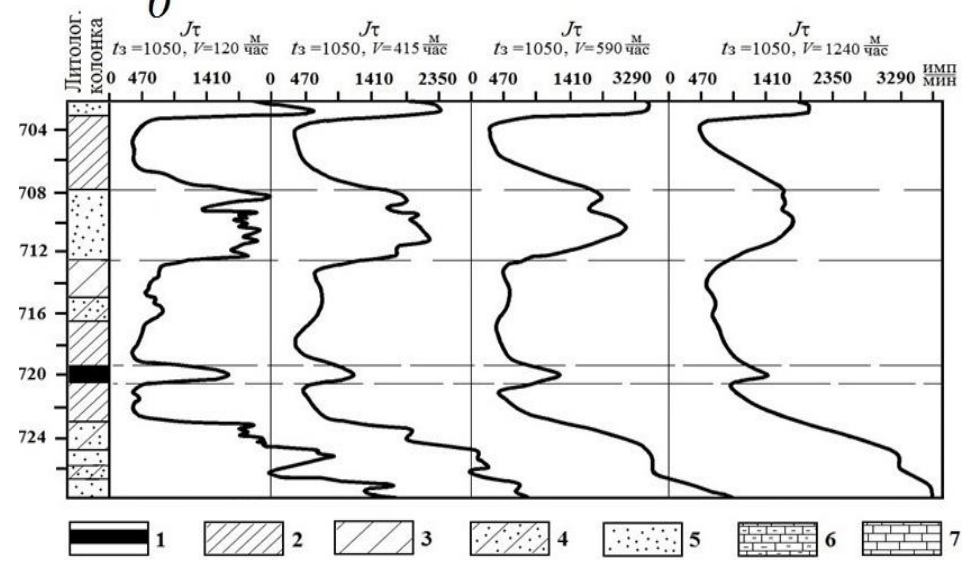

Pис. 5. Литологическое расчленение по диаграммам ИННК и БК пласта известняка сложного строения (a) и демонстрация изменения формы кривых ИННК, зарегистрированных с различной скоростью подъёма каротажного зонда (б): 1 - уголь, 2 -аргиллит, 3 - алевролит, 4 - алевролит крупнозернистый (песчаный), 5 песчаник, 6-известняк глинистый (мергель), 7 -известняк

Pic. 5. Lithological dismemberment through PNNL and Lateral Logging (LL) curves of the complex structured limestone layer (a) and demonstration of change in shapes of curves registered with different velocity of logging zond lifting (б): 1 -coal, 2 -argillite, 3 - aleurolite, 4 - aleurolite coarse-grained (sandy), 5 - sandstone, 6 -limestone clayey (marl), 7 - limestone 
Рис. 5, 6 иллюстрирует кривые ИННК, зарегистрированные с различной скоростью подъёма каротажного зонда $(V)$. Проведенный эксперимент показывает, что с увеличением $V$, соответственно, происходит сдвиг каротажных диаграмм. Можно заключить, что оптимальная величина $V$ не должна превышать 250 м/ч, а при детализации угольных пластов $V$ целесообразно уменьшать до 100 м/ч. Этот показатель соответствует скорости записи и в других методах радиоактивного каротажа на угольных месторождениях (гамма-гамма и гамма каротаж) [21].

Применение ИННК в рациональном комплексе каротажа на угольных месторождениях

Нормативными требованиями Государственной комиссии запасов Российской федерации (ГКЗ РФ) геофизические исследования в угольных скважинах могут быть использованы для: 1) определения последовательности залегания и литологической принадлежности пород угленосной толщи; 2) выявления в разрезах скважин угольных пластов и их стратиграфических признаков; 3) получения сведений о толщинах и структурно-текстурных особенностях угольных пластов; 4) определения отдельных качественных и количественных показателей углей; 5) характеристики тектонических разрывных нарушений, а также крепости и упруго-деформационных свойств углей и вмещающих пород; 6) изучения геотермического состояния угленосной толщи и пространственного положения (угол наклона и азимут) осей скважин. Геофизические измерения выполняются в скважине в цифровом виде с помощью аппаратурнометодических комплексов (АМК) и комплексными скважинными приборами. Детальность и разрешающая способность геофизических исследований определяются размерами скважинных датчиков и шагом квантования, который выбирается в зависимости от мощности и строения угольных пластов на месторождении и необходимости их детальных исследований. Шаг квантования для месторождений с тонкими и маломощными пластами (до 3,5 м) выбирается в пределах 0,02-0,03 м. Для месторождений с пластами средней и большой мощности (свыше 3,5 м) этот шаг может быть увеличен до 0,04-0,05 м. По всему стволу скважины выполняются измерения в масштабе глубин 1:200, а по интервалам угольных пластов - в масштабе 1:20 или 1:50. Масштаб 1:20 применяется на месторождениях с тонкими угольными пластами (до 3,5 м), при больших мощностях используется масштаб 1:50.

Согласно нормативным документам [12], рациональный комплекс методов каротажа угольных скважин состоит из основной части, которая выполняется во всех скважинах, и дополнительной, вводимой в этот комплекс в определенных условиях для решения геологических задач. Необходимость, состав и решаемые задачи дополнительной части обосновываются в проекте. На рис. 6 приведенный комплекс включает БК, метод кажущихся сопротивлений потенциал-зондом (КС-ПЗ), акустический каротаж (АК), радиоактивные методы гамма-гамма каротажа (ГГК), гамма каротажа
(ГК), ИННК и кавернометрию (КМ). Перечисленным комплексом полностью решаются задачи по детальному изучению стратиграфии геологического разреза скважины, выявлению в нём целевых объектов (угольных пластов), установлению соответствия последних положению в нормативном кластере. Анализ кривых показывает, что пласты углей как основной объект поисков и разведки однозначно выделяются всеми перечисленными методами. Следовательно, выполняются нормативные требования для угольного каротажа, согласно которым угольный пласт должен чётко устанавливаться по данным не менее трех каротажных кривых различных методов [12].

Здесь следует отметить, что в стандартном комплексе ведущим (основным) методом выделения угольных пластов является каротаж ГГК, в частности ГГК-С (селективный гамма-гамма каротаж с применением «мягких» источников гамма-квантов). Применение метода требует наличия радиоактивного источника с соответствующим его хранением и перевозкой в специальных свинцовых контейнерах. Эти условия могут быть реализованы только в стационарных геофизических партиях, функционирующих на территориях угольных бассейнов или месторождений, где планируются и выполняются регулярные геологоразведочные работы. В других случаях, когда объёмы таких работ предельно ограничены и территориально разрознены, использование радиоактивных источников не оправдывается экономическими затратами и следует искать альтернативную замену методу ГГК. Таким методом может являться ИННК. Поэтому целесообразно выполнить сравнительную оценку ГГК и ИННК на примере каротажных кривых, сопоставленных на рис. 6. Для этого первым порядком произведём анализ кривой ГГК-С. Эта модификация ГГК имеет преимущество перед другой модификацией ГГК-П (плотностной гамма-гамма каротаж с использованием «жёстких» источников гамма-квантов) за счёт наличия прижимного зонда, что существенно снижает влияние на показания интенсивности рассея-

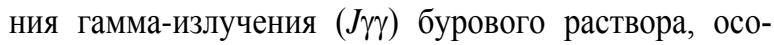
бенно в области каверн. Прижим прибора к стенке скважины позволяет наряду с низкоплотностными углями выделять и относительно высокоплотностные пласты известняков, которые больше по плотности аргиллито-песчаных отложений примерно на величину $0,25 \cdot 10^{-3} \mathrm{\kappa г} / \mathrm{M}^{3}$. Последние слабо дифференцированы между собой по плотности (разница не превышает

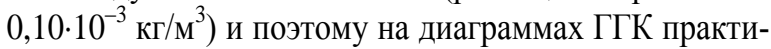
чески не разделяются. Большим недостатком метода ГГК-С является вероятность прихвата прибора в кавернах за счёт конструктивных особенностей прижимного устройства с соответствующим обрывом прибора и последующими затратными экономическими, административными и технологическими действиями по извлечению, а часто и «захоронению», радиоактивного источника. Учитывая этот факт, перейдём к рассмотрению кривых ИННК и подчеркнём позитивные стороны этого метода при совокупном анализе всего комплекса каротажа в угольной сква- 
жине. Начнём с факта возможностей регистрации методом ИННК всех имеющихся в разрезе угольных пластов и вероятности их однозначного истолкования посредством регистрации кривых в достаточно широком диапазоне временных задержек и представлению результатов в различных масштабах напряжений (имп/мин на 1 см). Из рассмотрения приведенных на рис. 6 кривых ИННК можно констатировать, что угольные пласты на этих диаграммах отмечаются положительными аномалиями при отношении $N_{\text {уг }}$ ля $/ N_{\text {apг }}>60$ (рис. 4, б). Для однозначного выделения угольного пласта необходимо пользоваться комплексом геофизических методов. Это же требование применимо и к методу ГГК. Например, при сравнении кривых ГГК-С и кавернометрии $\left(d_{c}\right)$, имеет место их почти строгая идентичность, что наталкивает на мысль о регистрации методом ГГК-С объёма бурового раствора в том или ином интервале, хотя в действительности кривая ГГК-С отображает дифференциацию пород по плотности, исключая действие бурового раствора за счёт прижима зондовой установки к стенке скважины. Учитывая вышеприведенное нормативное требование об установлении угольного пласта не менее тремя каротажными кривыми различных методов, замена ГГК-С методом ИННК может вполне иметь место, при том что второй альтернативой ГГКС является метод АК в режиме записи кривой интервального времени $(\Delta T)$. К третьему методу, однозначно разделяющему низкоомные антрациты и высокомные известняки, относятся модификации КС.

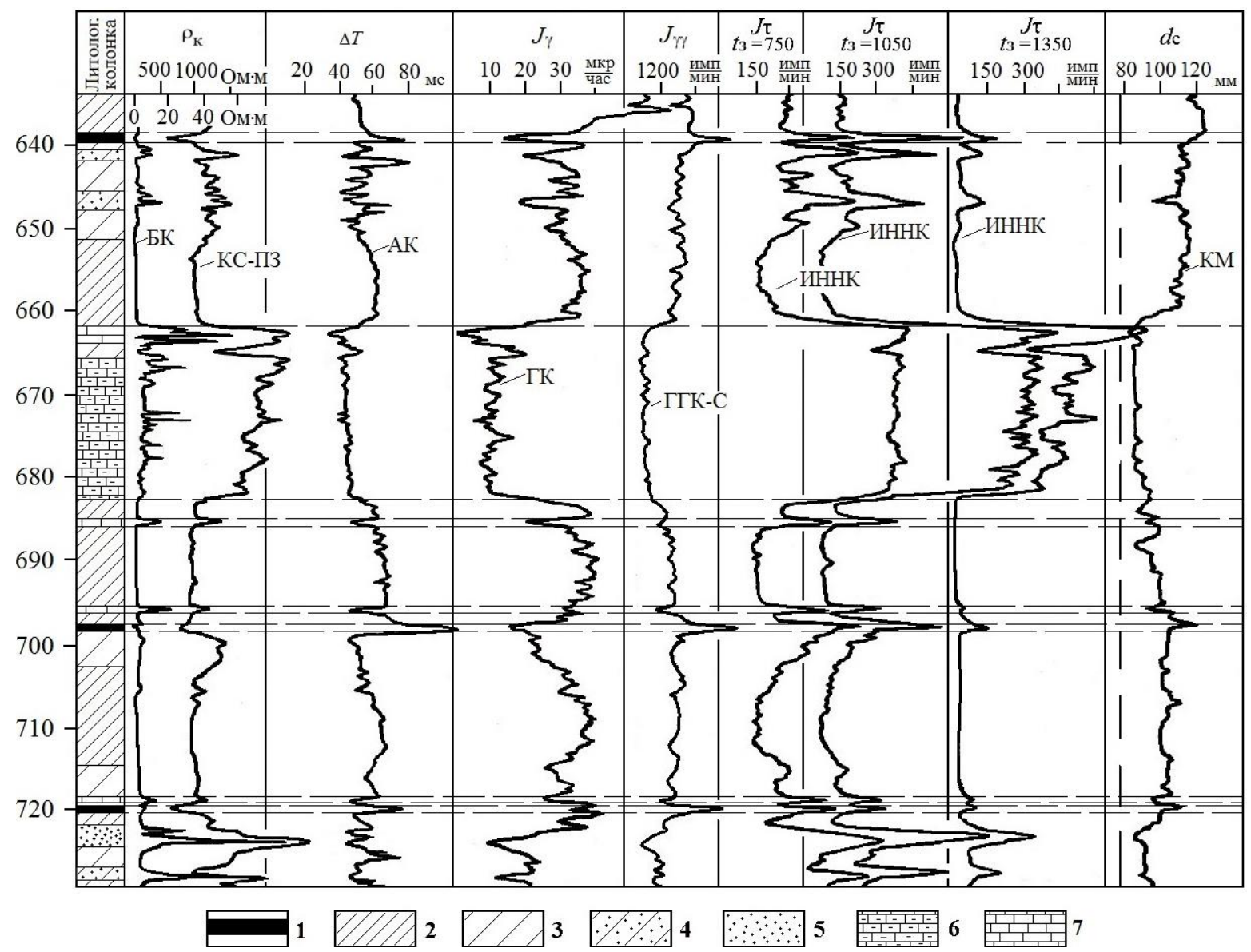

Рис. 6. Сопоставление каротажных кривых поискового комплекса и диаграмм ИННК. Восточный Донбасс. Участок Калиновский-Восточный: 1 - уголь, 2 - аргиллит, 3 - алевролит, 4 - алевролит крупнозернистый (песчаныгй), 5 - песчаник, 6-известняк глинистый (мергель), 7 - известняк

Pic. 6. Matching of well logging curves of the seeking complex and RINK diagrams. Eastern Donbass. Kalinovsky-Eastern site: 1 -coal, 2 - argillite, 3 - aleurolite, 4 - aleurolite coarse-grained (sandy), 5 - sandstone, 6 - limestone clayey (marl), 7 - limestone

\section{Заключение}

Обзор литературных источников показывает, что интерес к исследованиям по разработке и применению импульсных генераторов нейтронов в геологической отрасли, теоретическому обоснованию возникающих физикогеологических, геохимических и др. явлений весьма высок [1-6, 8, 13-19]. По данным А.П. Поляченко и Л.Б. Поляченко [1] этот этап является вторым всплеском по отношению к бурному периоду становления и развития ИННК в плане теоретических и методических его основ, который пришёлся на 60-70-е гг. минувшего столетия с последующим широким практическим применением в нефтегазовой отрасли и в значительно меньшей мере газовой, урановой, рудной и угольной геологии.

Россия располагает большими ресурсами и разведанными запасами углей. В перспективе промышлен- 
ное освоение этих запасов, особенно в сложных горно-геологических условиях и на больших глубинах, потребует выполнения геологоразведочных работ. На нефтегазовых месторождениях скважины также часто пересекают угленосные толщи и по углям оценивается степень эпигенетического преобразования всей толщи пород. Изучение и ввод в эксплуатацию углегазовых и газоугольных месторождений также требует новых методических решений и технологических подходов [20]. Поэтому появление новых задач, которые необходимо решать в процессе разведки угольных месторождений, в первую очередь связанных с безопасностью проведения горных работ и прогнозом опасных явлений: газоносности, выбросоопасности, устойчивости пород кровли и почвы угольных пластов, вызывает необходимость пересмотра существующего устаревшего комплекса геофизических исследований скважин (ГИС) на угольных месторождениях. Включение ИННК в стандартный комплекс исследования скважин на угольных месторождениях позволит существенно повысить результативность геологоразведочных работ на угольных и газоугольных месторождениях. В настоящей статье это подтверждается опытноэкспериментальными исследованиями углеразведочных скважин методом ИННК в Восточном Донбассе. Таким образом, можно заключить:

1. Современная элементная база и прогрессивное развитие компьютерных технологий дают мощный толчок новому витку развития методов ИНК в геологоразведочных и эксплутационных скважинах. Об этом свидетельствует широкий спектр научных публикаций.

\section{СПИСОК ЛИТЕРАТУРЫ}

1. Поляченко А.Л., Поляченко Л.Б. Развитие теоретикоинтерпретационного обеспечения импульсного нейтронного каротажа // Геофизика. - 2014. - № 3. - С. 32-40.

2. Велижанин В.А. Информационный потенциал обработки данных импульсного нейтронного каротажа // Каротажник. 2017. - № 278. - C. 101-111.

3. Выделение продуктивных интервалов в засолонённых коллекторах Чаяндинского месторождения по результатам исследований комплексом LITHO SCANNER / C.Г. Крекнин, К.В. Пушников, Р.Р. Сафин, Е.А. Карпекин, А.Ю. Филимонов, Г.С. Сардаров // Каротажник. - 2017. - № 282. - С. 30-41.

4. Estimation of the presence of coal using at the Soma Basin / Karavul Can, Karaman Hamza, Demi A. Serhat, Demirkol Askin // Asia Pacific Confederation of Chemical Engineering Congress 2015: APCCHE 2015, incorporating Chemeca 2015. - Melbourne: Engineers Australia, 2015. - P. 1029-1041.

5. Statistical analysis of pulsed-neutron well logs in monitoring injected carbon dioxide / A. Nicholas, N.W. Azzolina, M.E. Bosshart, J.A. Burton-Kelly, W. Hamling, D. Peck // International Journal of Greenhouse Gas Control. - 2018. - V. 75. - P. 125-133.

6. A method for evaluating gas saturation with pulsed neutron logging in cased holes / Juntao Liu, Shucai Li, Feng Zhang, Bo Su, Haijun Yang, Yongz hong Xu, Bin Miao, Hu Li // Journal of Natural Gas Science and Engineering. - 2018. - V. 59. - P. 354-362.

7. Физические основы импульсных нейтронных методов исследования скважин / Ю.С. Шимелевич, С.А. Кантор, А.С. Школьников и др. - М.: Изд-во «Недра», 1976. - 160 с.

8. Бортасевич В.С., Емельянов А.В., Черменский В.Г. Каротаж без химических источников нейтронов - шаг сделан // Каротажник. - 2014. - № 242. - С. 103-126.

9. Гольдин И.М., Зенков Ю.А., Шведов В.И. Опыт применения ИННК в угольной скважине. // Ядерно-геофизические методы. Новосибирск: Изд-во «Наука», 1972. - С. 291-294.
2. Развитие угольного каротажа исторически шло вслед за ГИС в нефтегазовой отрасли. Это предопределяет быструю адаптацию теоретических и аппаратурно-технологических разработок, а также программного обеспечения для внедрения в угольную геологию, в том числе по методам ИНК.

3. Исследования, выполненные авторами методом ИННК в Восточном Донбассе, позволили на экспериментальном материале уточнить оптимальные условия регистрации каротажных диаграмм ИННК и доказали высокую информативность метода в реализации поставленных геологической службой задач по разделению пород на литологические разности с выделением угольных пластов и определением их качественных и количественных показателей.

4. Проведенными экспериментами продемонстрирована возможность определения по данным ИННК марочного состава углей и их зольности, имеются предпосылки оценки тектонической нарушенности и устойчивости вмещающих пород в кровле и почве угольных пластов.

5. На основе сопоставления кривых ИННК с диаграммами электрического, радиоактивного, акустического каротажа и кавернометрии установлено, что метод ИННК органично вписывается в поисковый и детализационный комплексы каротажа на угольных месторождениях и может в конкретных геолого-геофизических и производственноэкономиических условиях заменять методы ГГК в случаях невозможности работ с радиоактивными источниками.

10. Поляченко А.Л., Попов В.В., Клименко Н.В. Применение импульсного нейтронного каротажа на угольных месторождениях // Разведочная геофизика. - М.: Изд-во «Недра», 1984. Вып. 98. - С. 117-126.

11. Кучурин Е.С. Способ определения зольности и теплотворной способности ископаемых углей. URL: www.findpatent.ru/ patent/207/2075099.html (дата обращения 15.01.2020).

12. Техническая инструкция по проведению геофизических исследований в скважинах / под ред. Н.Н. Сохранова - М.: Изд-во «Недра», 1985. - 216 с.

13. Аппаратурно-методические комплексы для исследования рудных, угольных и гидрогеологических скважин / В.Т. Перелыгин, К.А. Машкин, О.Е. Рыскаль, А.Г. Коротченко, Р.Г. Гайнетдинов, В.М. Романов, В.Л. Глухов, П.А. Сафонов, А.Ф. Камалтдинов, А.Н. Огнев, И.Х. Шабиев // Каротажник. - 2015. - № 255. - С. 99-127.

14. A method for determining density based on gamma ray and fast neutron detection using a $\mathrm{Cs} 2 \mathrm{LiYCl} 6$ detector in neutron-gamma density logging / Zhang Feng, Zhang Robin, P. Gardne, Huizhong Yan, Guoli Wu, Lili Tian, Qian Chen, Yongzhou Ti // Applied Radiation and Isotopes. - 2018. - V. 142. - P. 77-84.

15. Development of a new deuterium-deuterium (D-D) neutron generator for prompt gamma-ray neutron activation analysis / K. Bergaoui, N. Reguigui, C.K. Gary, C. Brown, J.T. Cremer, J.H. Vainionpaa, M.A. Piestrup // Applied Radiation and Isotopes 2014. - V. 94. - P. 319-327.

16. A comparative study on the neutron-gamma density and gammagamma density logging / Zhang Feng, Zhang Chao Yuan, Xinguang Wang, Xiaoyang Zhang // Journal of Petroleum Science and Engineering. - 2019. - V. 176. - P. 792-799.

17. Gan Th., Balmain B., Sigbatullin A. Formation evaluation logoff results comparing new generation mining-style logging tools to conventional oil and gas logging tools for application in coalbed methane (CBM) field development // Journal of Natural Gas Science and Engineering. - 2016. - V. 34. - P. 1237-1250. 
Известия Томского политехнического университета. Инжиниринг георесурсов. 2020. Т. 331. № 2. 151-161

Фоменко Н.Е., Попов В.В., Коваленко А.С. Исследование углеразведочных скважин методом импульсного нейтрон-нейтронного ...

18. Neutron beam profilometer on the base of double-sided silicon strip detectors / N.I. Zamyatin, V.M. Bystritsky, Y.N. Kopach, F.A. Aliyev, D.N. Grozdanov, N.A. Fedorov, C. Hramko, I.N. Ruskov, V.R. Skoy, V.M. Slepnev, D. Wang, E.V. Zubarev // Nuclear Instruments and Methods in Physics Research Section A: Accelerators, Spectrometers, Detectors and Associated Equipment. - 2018. - V. 898. - P. 46-52.

19. Hatherly P. Overview on the application of geophysics in coal mining // International Journal of Coal Geology. - 2013. - V. 114. P. 74-84.

\section{Информация об авторах}

Фоменко H.E., доктор геолого-минералогических наук, профессор кафедры геоэкологии и прикладной геохимии Института наук о Земле Южного федерального университета.

Попов В.В., доктор технических наук, профессор кафедры нефтегазовых техники и технологии Факультета геологии, горного и нефтегазового дела Южно-Российского политехнического университета.

Коваленко A.C., кандидат технических наук, старший научный сотрудник акционерного общества «Всероссийский научно-исследовательский геологоразведочный институт угольных месторождений». разведочных скважинах // Каротажник. - 2003. - № 105. C. 80-89. ческими методами. - М.: Изд-во «Недра», 1980. - 320 с.

Поступила 24.01.2020 г.
20. Попов В.В. Комплексы геофизических исследований в угле-

21. Гречухин В.В. Изучение угленосных формаций геофизи- 
DOI 550.832 .54

\title{
STUDY OF COAL EXPLORATION WELLS USING THE PULSED-NEUTRON-NEUTRON LOGGING
}

\author{
Nikolay E. Fomenko1, \\ fnegeophyskohle@yandex.ru
}

Viktor V. Popov'2, viktor_popov_34@mail.ru

Andrey S. Kovalenko3, a_kovalenko_77@mail.ru

1 Southern Federal University, 40, Sorge strret, Rostov-on-Don, 344090, Russia.

2 South Russian Polytechnic University, 132, Prosveshchenia street, Novocherkassk, 346428, Russia.

${ }^{3}$ All-Russian Scientific Research Geological Exploration Institution of Coal Deposits, 200/1, housing 3, Stachki avenue, Rostov-on-Don, 344090, Russia.

\begin{abstract}
Relevance of the research is defined by the necessity in optimization of coal exploration well geophysical researches by means of pulsedneutron-neutron logging. Formulation of the problem is conditioned by modern tendencies of coal industry development and new instrumental and technical elaborations at exploration and borehole geophysics.

The aim of the research is to show the opportunities and effectiveness of pulsed-neutron-neutron logging at coal exploration wells on materials of experienced-experimental works in Eastern Donbass.

Object: logs of pulsed-neutron-neutron logging registered in coal exploration wells of Eastern Donbass.

Methods: analysis of pulsed neutron-neutron logging logging curves for the effectiveness of using the method in a standard complex for solving problems posed by the geological service for identifying: 1) targets, i. e. coal seams with the definition of their position in the section; 2) rocks containing coal seams.

Outcomes of the research. The application of pulsed-neutron-neutron logging for the study of geological sections of the coal wells was justified. The authors have studied qualitative and quantitative characteristics of thermal neutrons lifetime in rocks of the coal-bearing strata. The paper demonstrates the opportunities of the method by estimation of mark composition of coal and their ash content. The authors carried out the well logging curves matching registered at differ temporary delays and with different velocity of logging zond lifting on subject to choosing optimal conditions of geophysical work by this method. It was established that all the lithological differences including thin coal layer are unambiguously distinguished by the pulsed-neutron-neutron logging method. There authors analyzed the pulsedneutron-neutron logging resolution on the background of well logging curves of geophysical well survey complex including the methods of electrical, radioactive, acoustical well logging and caliper. The accent was made on positive sides and drawbacks of gamma-gamma well logging with soft source. The authors suggested replace GGK-S research by pulsed-neutron-neutron logging logging in the presence of organizational and technical difficulties.
\end{abstract}

\section{Key words:}

Pulsed-neutron-neutron logging, coal exploration well, thermal neutron lifetime, rational logging complex, argillite, aleurolite, sandstone and limestone layers, Eastern Donbass.

\section{REFERENCES}

1. Polyachenko A.L., Polyachenko L.B. Development of the theoretic-interpretational provision of pulsed-neutron logging. Geophysics, 2014, no. 3, pp. 32-40. In Rus.

2. Velizhanin V.A. Informational potential of the pulsed-neutron logging data processing. Karotazhnik, 2017, no. 278, pp. 101-111. In Rus.

3. Kreknin S.G., Pushnikov K.V., Safin R.R., Karpekin E.A., Filimonov A.Yu., Sardarov G.S. Allocation of the productivity intervals in the saline collector of Chayandinsk deposit by outcome research of LITHO SCANNER complex. Karotazhnik, 2017, no. 282, pp. 30-41. In Rus.

4. Can K., Hamza K., A Serhat D., Askin D. Estimation of the presence of coal using at the Soma Basin. Asia Pacific Confederation of Chemical Engineering Congress 2015: APCCHE 2015, incorporating Chemeca 2015. Melbourne: Engineers Australia, 2015. pp. 1029-1041.

5. Nicholas A., Azzolina N.W., Bosshart M.E., Burton-Kelly J.A., Hamling W., Peck D. Statistical analysis of pulsed-neutron well logs in monitoring injected carbon dioxide. International Journal of Greenhouse Gas Control, 2018, vol. 75, pp. 125-133.

6. Liu J., Li S., Zhang F., Su B., Yang H., Xu Y., Miao B., Li H. A method for evaluating gas saturation with pulsed neutron logging in cased holes. Journal of Natural Gas Science and Engineering, 2018, vol. 59, pp. 354-362.

7. Shimelevich Yu.S., Kantor S.A., Shkolnikov A.S. Fizicheskie osnovy impulsnykh neytronnykh metodov issledovaniya skvazhin [Physical basis of the pulsed-neutron methods well research]. Moscow, Nedra Publ., 1976. 160 p.

8. Bortasevich V.S., Emelyanov A.V., Chermenskiy V.G. Logging without chemical source of neutrons - step is done. Karotazhnik, 2017, no. 242, pp. 103-126. In Rus.

9. Goldin I.M., Zenkov Yu.A., Shvedov V.I. Opyt primeneniya INNK v ugolnoy skvazhine [Experience of pulsed-neutron-neutron logging applying in coal well]. Yaderno-geofizicheskie metody [Nuclear geophysical techniques]. Novosibirsk, Nauka Publ., 1972. pp. 291-294.

10. Polyachenko A.L., Popov V.V., Klimenko N.V. Primenenie impulsnogo neytronnogo karotazha na ugolnykh mestorozhdeniyakh [Applying pulsed-neutron-neutron logging at coal deposits]. Razvedochnaya geofizika [Exploration geophysics]. Moscow, Nedra Publ., 1984. Iss., 98, pp. 117-126.

11. Kuchurin E.S Sposob opredeleniya zolnosti i teplotvornoy sposobnosti iskopaemykh ugley [A way of determining ash and calorific value of fossil coals]. Available at: www.findpatent.ru/patent/ 207/2075099.html (accessed 15 January 2020). 
12. Tekhnicheskaya instruktsiya po provedeniyu geofizicheskikh issledovaniy v skvazhinakh [Instrumental-methodical complexes for ore, coal and hydrogeological wells]. Ed. by N.N. Sokhranov. Moscow, Nedra Publ., 1985. 116 p.

13. Perelygin V.T., Mashkin K.A., Ryskal O.E., Korotchenko A.G., Gaynetdinov R.G., Romanov V.M., Glukhov V.L., Safonov P.A., Kamaltdinov A.F., Ognev A.N., Shabiev I.Kh. Instrumentalmethodical complexes for ore, coal and hydrogeological wells research. Karotazhnik, 2017, no. 255, pp. 99-127. In Rus.

14. Feng Z., Robin Z., Gardne P., Yan H., Wu G., Tian L., Chen Q., Ti Y. A method for determining density based on gamma ray and fast neutron detection using a $\mathrm{Cs} 2 \mathrm{LiYCl} 6$ detector in neutrongamma density logging. Applied Radiation and Isotopes, 2018, vol. 142 , pp. 77-84.

15. Bergaoui K., Reguigui N., Gary C.K., Brown C., Cremer J.T., Vainionpaa J.H., Piestrup M.A. Development of a new deuteriumdeuterium (D-D) neutron generator for prompt gamma-ray neutron activation analysis. Applied Radiation and Isotopes, 2014, vol. 94, pp. 319-327.

16. Feng Z., Chao Yuan Z., Wang X., Zhang X. A comparative study on the neutron-gamma density and gamma-gamma density logging. Journal of Petroleum Science and Engineering, 2019, vol. 176, pp. 792-799.

\section{Information about the authors}

Nikolay E. Fomenko, Dr. Sc., professor, Southern Federal University.

Viktor V. Popov, Dr. Sc., professor, South Russian Polytechnic University.

Andrey S. Kovalenko, Cand. Sc., senior researcher, All-Russian Scientific Research Geological Exploration Institution of Coal Deposits.
17. Gan T., Balmain B., Sigbatullin A. Formation evaluation logoff results comparing new generation mining-style logging tools to conventional oil and gas logging tools for application in coalbed methane (CBM) field development. Journal of Natural Gas Science and Engineering, 2016, vol. 34, pp. 1237-1250.

18. Zamyatin N., Bystritsky V., Kopach Y., Aliyev F., Grozdanov D., Fedorov N., Hramko C., Ruskov I., Skoy V., Slepnev V., Wang D., Zubarev E. Neutron beam profilometer on the base of double-sided silicon strip detectors. Nuclear Instruments and Methods in Physics Research Section A: Accelerators, Spectrometers, Detectors and Associated Equipment, 2018, vol. 898, pp. 46-52.

19. Hatherly P. Overview on the application of geophysics in coal mining. International Journal of Coal Geology, 2013, vol. 114, pp. 74-84.

20. Popov V.V. Geophysical research complexes in coal exploration wells. Karotazhnik, 2017, no. 105, pp. 80-89. In Rus. metodami [Coal formations study by geophysical methods]. Moscow, Nedra Publ., 1980. 320 p.

Received: 24 January 2020.
21. Grechukhin V.V. Izuchenie uglenosnykh formatsy geofizicheskimi 